\title{
Year 5 Pupils' Perception on Guided Reciprocal Peer Questioning (GRPQ) Strategy in Reading Comprehension: A Conceptual Paper
}

\author{
Hanis Wardah Parjan, Maslawati Mohamad \\ Universiti Kebangsaan Malaysia, Bangi, Malaysia \\ Email:p106106@siswa.ukm.edu.my,maslawati@ukm.edu.my
}

How to cite this paper: Parjan, H. W., \& Mohamad, M. (2021). Year 5 Pupils' Perception on Guided Reciprocal Peer Questioning (GRPQ) Strategy in Reading Comprehension: A Conceptual Paper. Creative Education, 12, 1643-1654.

https://doi.org/10.4236/ce.2021.127125

Received: June 23, 2021

Accepted: July 23, 2021

Published: July 26, 2021

Copyright ( 2021 by author(s) and Scientific Research Publishing Inc. This work is licensed under the Creative Commons Attribution International License (CC BY 4.0).

http://creativecommons.org/licenses/by/4.0/

\begin{abstract}
Researchers have studied a variety of effective teaching strategies to be employed in English as a Second Language reading classroom. The studies done on the Guided Reciprocal Peer Questioning (GRPQ) strategy have been proven to provide a wide range of benefits to the pupils' performance in the ESL classrooms especially towards their reading comprehension skills. Nevertheless, most of the studies focused more on the usage of GRPQ strategy towards secondary and tertiary students. The purpose of this paper is to provide the information on the benefits of GRPQ strategy and the perception of the primary level pupils in ESL reading classroom. The participants of this study are from a primary school in a sub-urban area. There will be 34 intermediate Year 5 pupils involved in this study. The researchers will conduct a mixed methods research to investigate the pupils' perception on the use of GRPQ strategy in ESL reading classroom. Questionnaire, semi-structured interview and observation note will be used as data collection tools. The findings of this study are hoped to provide some insights on the benefits and perception of GRPQ strategy towards primary school pupils in promoting their reading comprehension.
\end{abstract}

\section{Keywords}

Guided Reciprocal Peer Questioning, GRPQ, Reading Comprehension, Perception, Year 5 Pupils

\section{Introduction}

According to Hesham (2006), reading skill is the receptive skill that encourages and promotes indirect communication process between the reader and the writ- 
er. Hesham (2006) further added that reading involved the perception and thought process of an individual and this is a complex activity to be performed. There are two inter-related processes to be performed during reading which are word recognition and comprehension. He adds that the process of recognizing how written symbols conform to the spoken language is called the process of word recognition whereas the process of making sense of words, tenses, sentences, and connected text is called comprehension (Yuniarti et al., 2019).

As comprehension passages become longer and more complex, the reading difficulties among the primary school pupils to comprehend the reading materials escalated especially in the Malaysian context (Amalia \& Muhammadun, 2018). Although proactive attempts are made, the pupils still encounter problems in making sense of the texts. Furthermore, they added that this problem had led the pupils to feel frustrated with their reading comprehension skills. The need to provide as well as to equip the pupils with the necessary skills to overcome the struggles of comprehending reading texts needs to be addressed by the researchers. The pupils require modeling and guided instruction to grasp the main ideas of the text besides being able to answer and ask comprehension questions to generate understanding. In order to accommodate this difficulty, a teaching strategy named Guided Reciprocal Peer Questioning (GRPQ) was devised. According to King (2002), the GRPQ strategy is a strategy that collaborates with the cooperation and questioning techniques between the pupils and their peers. It is to achieve the aim of generating questions and providing small group focused discussion sessions to develop their reading comprehension skills.

GRPQ strategy emphasizes the importance of using the combination of questioning strategy and cooperative learning all at the same time. The teachers and educators must adapt a strategy that can actively promote the development of meaningful and effective lessons in the classroom (Matinde, 2019). Previous studies have displayed that the GRPQ strategy offers the pupils the stimulants needed to do advanced comprehension of the reading materials, managing complex reading demand successfully, nurture self-efficacy in reading besides becoming active and engaging learners (Pan, 2014; Yuniarti et al., 2019; Amalia \& Devanti, 2016; Matinde, 2019; Tanaka \& Sanchez, 2016; Amalia \& Muhammadun, 2018). Additionally, the pupils will have the opportunity to gain new knowledge, develop their communication skills, comprehension skills, and also teamwork. This proposed study will highlight more on the perception of the primary school pupils towards the use of the GRPQ strategy since this strategy is rarely being employed in Malaysia's education setting. The use of GRPQ strategy in the ESL reading classroom will be an innovative way to teach them reading comprehension and enhance their comprehension skills. The research question for this study is:

- What are the perceptions of Year 5 pupils on the use of Guided Reciprocal Peer Questioning (GRPQ) strategy towards their reading comprehension skills? 


\section{Literature Review}

\subsection{Benefits of Guided Reciprocal Peer Questioning (GRPQ) Strategy}

GRPQ strategy is one of the strategies where pupils will gain a lot of benefits especially in developing their language skills. According to Yuniarti, Rufinus and Wijaya (2019), through the GRPQ strategy, pupils and the teachers will gain chances to alternately ask questions to each other with their questions following the reading session. This results in pupils developing questioning behaviour, adopt an active and positive attitude towards reading, obtain clear purposes of reading and foster their independent reading comprehension skill which in returns make reading as an interesting and enjoyable activity for them (Yuniarti et al., 2019).

According to Gelmini-Hornsby, Ainsworth, and O'Malley (2011), the GRPQ strategy allows the pupils to question their peers' ideas, put forth alternatives, and request explanations. They added that the pupils could oppose or resist the conflicting perspectives and opinions as well as the diverse understanding of the content of the text that they have read. In an attempt to settle these cognitive disagreements, the pupils and their peers need to find their middle ground by trying to understand each other's opinions, clarify their ideas, provide an appropriate statement to defend their ideas, and convince their peers. Furthermore, the pupils will experience the beauty of encouragement, assistance and success which then can provide enhancement in their motivation to learn (Pan \& $\mathrm{Wu}$, 2013). According to Pan (2014), GRPQ ensures the pupils actively engaging with the text and provides them with the opportunities to work with others on the reading materials as well as achieving a higher level of comprehension skills.

As a conclusion, the benefits of GRPQ widely cover not only from the advancement of reading comprehension itself but also towards the social and cognitive growth of the pupils thus making it one of the most effective strategies to be used by the teachers and educators in the teaching and learning process especially in primary ESL classroom.

\subsection{The Development of Reading Comprehension in GRPQ Strategy}

Reading skills and comprehension skills are related to each order because the goal of reading is for the readers to be able to comprehend the content or the information that they read from a reading text (Amelia \& Kamalasari, 2018). According to Amalia and Devanti (2016), reading is a process where the readers digest the content and are able to retrieve information from the text. When comprehending the text, it does not only refer to the ability to be able to understand its context and words but also the gist of the whole paragraphs and text.

Questioning while reading is one of the keys to develop excellent comprehension (Gelmini-Hornsby et al., 2011). Thus, the pupils must be proficient in constructing their own meaningful and effective questioning strategies. According to Flood and Peter (1984), questioning is necessary to stimulate and lead the 
thinking process but proper guidance and additional instruction are still needed as to affect the pupils' comprehension development positively. Simply giving orders to orchestrate reading comprehension tasks in a group and asking them to collaborate will not necessarily lead them to engage in interactive discussion (Gelmini-Hornsby et al., 2011). There are three steps to administer GRPQ strategy in a reading comprehension lesson. They are self-questioning, peer-questioning and discussion (Pan, 2014).

Based on Figure 1, this strategy begins with the teacher providing the pupils with an overview and rationale of the activity that will be conducted during the lesson. The sharing of overview and rationale of the activity is done before the pupils read the reading text. This is carried out to ensure a smooth flow of the lesson. Next, the teacher will provide the necessary introduction by presenting the questions and the techniques to formulate specific questions related to the text. The GRPQ strategy will then begin with the first step named self-questioning phase. During this step, pupils will be given another text and provided with the time to read independently and encourage to generate their questions with some guidance by the teacher if necessary. The cognitive process that happens here requires the pupils to put additional effort in reading the text, identify the main ideas, investigate the relationships that exist between the ideas while connecting them to their prior knowledge. This will facilitate the comprehension of the text effectively (Gelmini-Hornsby et al., 2011; Pan, 2014).

The second step is peer-questioning. During the peer-questioning phase, pupils will be divided into small groups of four to five members. Pupils together with their peers will have a questioning and answering session where they will use their independently generated questions from the first phase. Peer-questioning phase acts as a platform for the pupils and their peers to question their ideas, put forth alternative and demand elaboration. The cooperation between the pupils and their peers must be appropriate as to produce an engaging and productive discussion. According to Bearison (1982), this phase relates to the theories of the social construction of knowledge in which the pupils will receive some social pressure by their peers to suggest appropriate questions and provide satisfactory answers. Such conceptual restructuring process will not only promote the progression of identifying accurate and effective representation of the text read but also will lead to advance comprehension of the text as well as improving their reading performance.

Lastly, the third step, which is the discussion step. In this step, a thorough

\begin{tabular}{|l|l|l|l|}
\hline \multicolumn{1}{|c|}{ Induction } & \multicolumn{1}{c}{ Self-Questioning } & \multicolumn{1}{c}{ Peer Questioning } & \multicolumn{1}{c}{ Discussion } \\
- Overview & - Independent & - Group work & - Whole class \\
- Introduction & reading & - Ask and answer & - Sharing and \\
- Providing & - Independent \\
examples & generation of \\
- Guided reading & questions & questions & feedback \\
& & & \\
\hline
\end{tabular}

Figure 1. Steps to implement Guided Reciprocal Peer Questioning (GRPQ) strategy. 
discussion will be done by incorporating the inputs received by the pupils from their interactive discussion with their peers. During this step, teacher will guide the pupils to share and clarify any misunderstanding of the text read. The pupils will gain the opportunity to use their reasoning skills and critically process their discussion with their peers earlier. In the end, all of these steps in GRPQ strategy will promote reading comprehension of the pupils effectively and positively.

\subsection{Related Past Studies}

\subsubsection{Local Past Studies}

The explanation and examples of related past studies will be discussed in two parts, local context and international context. The studies on the topic of Guided Reciprocal Peer Questioning (GRPQ) strategy focus on reading comprehension have been conducted in various countries. However, none of these studies have addressed the primary school pupils' point of view. In the local context, a study was done by Tan, Tan and Norlida (2011), which focused on the effects of Reciprocal Peer Questioning (RPQ) strategy towards 68 Sixth-Form students in Malaysia. In this study, the researchers discovered that the strategy has a significant impact on the students' perception and also towards their reading comprehension. Positive inputs have been gained through their research validating the statement that GRPQ strategy provided an alternative that is effective for the pupils to construct meanings from texts and how to work cooperatively during a group discussion during a reading comprehension class. Moreover, Tan et al. (2011) also mentioned that this strategy promotes the pupils' self-regulatory and monitoring skills which can develop and produce autonomous readers.

Besides that, there is also another study by Shamsiah, Wong and Chan (2011). In this research, the researchers aimed to investigate the effectiveness of Reciprocal Peer Questioning (RPQ) in supporting blended learning of the 111 undergraduate students from IT discipline and non-IT discipline faculties. The participants were separated into two groups that consist of a mix of good and weak students. The finding of this study highlighted the positive feedback of the strategy in which it helps the students to improve their performance. The study also mentioned that the strategy even though had been used widely in many higher educational institutions, was a new thing towards the students and the lecturers. Next is a study by Nurul Nadwa, Noor Dayana, Norraffandy and Meijden (2020). The researchers investigated the pattern of critical thinking process in online Reciprocal Peer Questioning (RPQ) on 29 second-year undergraduate students revealed that the participants can engage in a rich and critical discussion online using the strategy. The questions posed by the participants during the strategy had influenced them to attain higher level of critical thinking in which they were able to ask questions based on their background knowledge and independent comprehension of the text. The participants also perceived the strategy positively. This study highlighted the finding of the students obtaining the ability to learn to be a critical thinker starting from a shallow learning and proactively towards a deeper learning which involved the students to derive con- 
clusions, associate ideas and produce provocative arguments.

\subsubsection{International Past Studies}

In the international context, a study by Pan (2014) involving 78 participants of EFL college students in Taiwan on the effects of Reciprocal Peer Questioning (RPQ) strategy on their reading comprehension is done. The study employed that the RPQ strategy had a higher effectiveness towards students with high and medium proficiency level and only limited effects were observed from students with low proficiency level. The finding indicated that through RPQ strategy, the reading comprehension of the students was actively promoted and that supported the findings of the previous local studies mentioned before (Tan et al., 2011; Shamsiah et al., 2011; Nurul Nadwa et al., 2020). Further into the research, the researchers also mentioned that this strategy managed to successfully nurture a more positive perception and attitude towards learning reading comprehension and strongly recommended teachers and educators to use as well as to adapt the RPQ strategy in the English classroom.

Another study by Tanaka and Sanchez (2016) also emphasized the positive findings from the 20 first-year Japanese college students who participated in the study. The study investigated the perception of the participants towards Guided Reciprocal Peer Questioning (GRPQ) strategy in cooperative reading activities. The claims made by the participants included them being able to understand the content and gist of the text better and that the strategy succeeds in improving their speaking skills as well. Furthermore, GRPQ strategy had managed to help them in discovering other elements in the text in which they would not have seen unless asked apart from raising their meta-cognitive awareness. So far, both international studies demonstrate positive output on the effectiveness of the GRPQ strategy. A study by Yuniarti, Rufinus and Wijaya (2019) on the use of Guided Reciprocal Peer Questioning (GRPQ) strategy in teaching reading comprehension was also done on the 34 eighth grade students of a high school in Indonesia. The researchers administered pre-test and post-test to see the difference between before and after the strategy was implemented. The study stressed on the intentions done by the researchers to provide an alternative for the students to have better comprehension of the text read. In addition, the study found that the students showed improvement in their achievement in the test as the mean score of the post-test was better than the mean score of the pre-test. This brought about the effect size of Highly Effective for the use of the GRPQ strategy in reading comprehension lesson.

Based on all the studies mentioned above, it is clear that GRPQ strategy results in positive effects towards the development of reading comprehension skill. Therefore, the pupils and teachers have positive perception towards the GRPQ strategy. Past studies have established that GRPQ strategy is an effective and constructive strategy in promoting reading comprehension besides encouraging the pupils to be autonomous readers and also promote higher thinking process. Hence, it would be wise for the educators to utilize this strategy as one of the in- 
terventions in reading comprehension lessons.

\subsection{Related Theories}

\subsubsection{Questioning Strategies in Reading}

According to Pan (2014), questioning is a process that involved the learners to comprehend the text read by inquiring questions before, during and after the reading. There is a set of steps in questioning strategies that guides the learners to ask questions while reading and also search for answers. Pan (2014) also mentioned three underlying theoretical perspectives of questioning strategy. They are active processing, meta-cognitive and schema theory. Active processing theory presumes that the learners need to grasp and make sense of a text actively by asking and answering during the reading session. When this is done, the learners' perception of the text can be affected and this includes their understanding of the text and the list of information contained in the text read (Natter \& Berry, 2005).

Next in line is the meta-cognitive theory. This theory explained about the use of questioning in assisting the learners to monitor the level of their comprehension of the text through the ability of the learner to identify key information in the text and how the learners regulate their strategies when facing difficulties while reading. According to Amalia and Devanti (2016), while reading, learners can effectively regulate their thinking to improve their understanding of the text by applying strategies such as internal talk or self-questioning, reflecting and being aware of their strength and weaknesses. This will result in a more productive output of reading. The third and the last theory associated with the questioning strategy would be the schema theory. This theory assumes that the strategy of questioning while reading will activate the prior knowledge of the learners in interpreting the information contained in the text and restructuring their schemata (Pan, 2014). The learners' schemata represent the learners' knowledge about certain concepts or objects or even the relationships between the situations, events and actions related. When reading, learners will try to connect or associate all the knowledge and information that they know to the information they obtained from reading, hence, promoting their comprehension of the text with the stored information that they have.

Based on the integration of the three theories above, it is clear that questioning strategy will not only increase the comprehension level of the learners towards the text read but also the involvement and engagement of the learners with the text. By asking questions while reading, the learners are forced to identify pertinent ideas, explain them and connect the ideas to their background knowledge (Gelmini-Hornsby, 2011). As according to Pan (2014), the more questions generated and asked by the learners, the more explicit the information gained which will increase the comprehensiveness of their reading. All of this can be seen to happen during the self-questioning phase. In this phase, pupils allocate their time to read independently and generate their questions with some guidance by the teacher. The active processing, meta-cognitive and schematic 
process will happen here in which it will help the pupils to put additional effort in reading the text, identify the main ideas, investigate the relationships that exist between the ideas while connecting them to their prior knowledge (Gelmini-Hornsby et al., 2011).

\subsubsection{Sociocultural Theory}

The GRPQ strategy includes the discussion between peers in the second phase. It is the peer-questioning phase. This phase adapts the sociocultural theory. The cooperative learning element of this strategy instigates the Zone of Proximal Development or ZPD by Vygotsky (1978).

Based on Figure 2, ZPD is the distance between the developmental level and potential level that depends on guidance from an adult/s or a more capable peer/s. Vygotsky (1978) claims that learning will take place through social interactions and that learning occurs specifically in the Zone of Proximal Development in collaboration with a more knowledgeable other/s. The proponents of ZPD propose the idea of a student who successfully completes a difficult task through the assistance of more knowledgeable others. Therefore, the proponents of ZPD encourage cooperative learning to complement and reinforce students' understanding on the subject matter. After understanding a text diverse activities could be carried out to promote higher-level thinking skills as well as oral communication skills through social interactions.

According to Tanaka and Sanchez (2016), cooperative learning is a pedagogical method whereby the pupils interact with each other apart from assisting each other to sort out problems and accomplish a project or tasks to maximize their learning in order to achieve mutual goals. The crucial concept of cooperative learning would be positive interdependence where both pupil and peer consider the fact that they need each other to conclude a task. Cooperative learning encourages collaborative works towards the aim of promoting each other's learning (Tanaka \& Sanchez, 2016). Through cooperative learning, it is believed that pupils

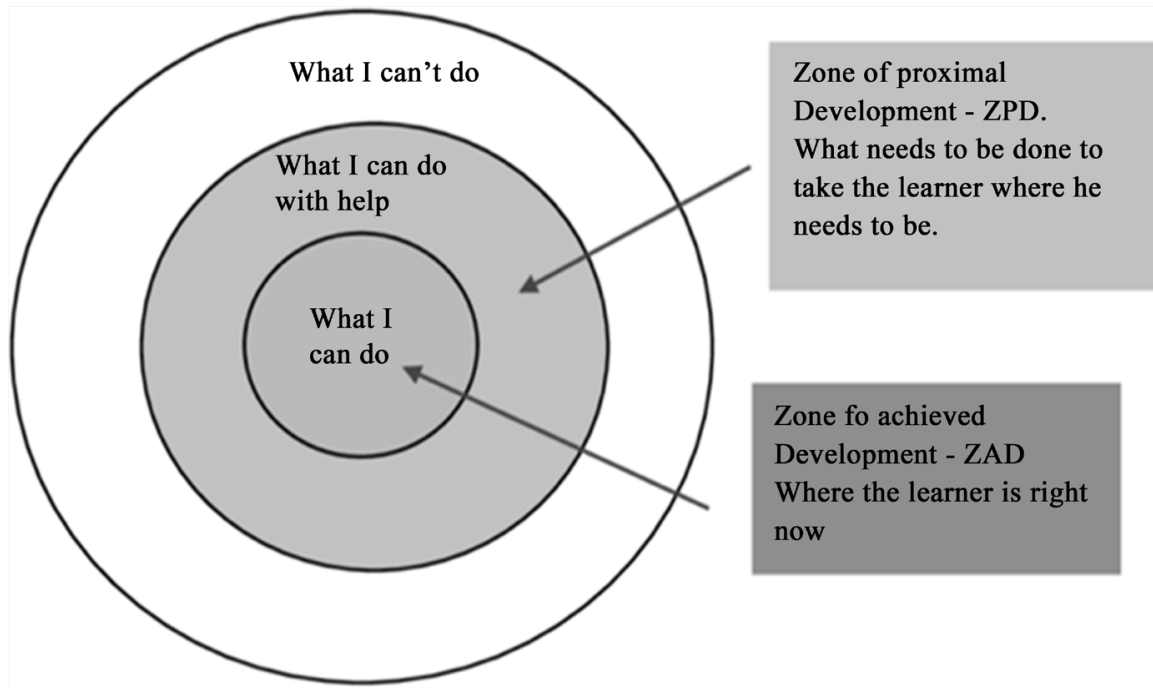

Figure 2. Zone of proximal development (Vygotsky, 1978). 
will be able to learn better when adequately guided through the ZPD when they are working with their peers. This can be seen in the GRPQ strategy in which the pupils are required to discuss their questions and answers together during a reading comprehension session. By making a joint effort, the pupils can complement and build on each other's comprehension with the premise of them having enough knowledge and understanding of the text read. Even during the discussion, pupils may face difficulties in comprehending the reading text as they may be lacking in their reading skills or domain-specific knowledge. A state of disequilibrium or the rise of uncertainty and conflict can occur. The pupils should be guided by the teacher to proceed in addressing the misunderstandings and clarify the misconceptions (Tanaka \& Sanchez, 2016).

\subsection{Summary}

This chapter states the benefits of GRPQ strategy and the process of reading comprehension development through the use of GRPQ strategy. Other than that, the related local and international past studies as well as the related theories for GRPQ strategy are also elaborated. Thus, based on the elaboration and explanation presented in this chapter, it is evident that the use of GRPQ strategy is relevant in improving the reading comprehension skill of the primary school pupils as intended by this paper.

\section{The Proposed Study}

Most of the studies available focus more on the GRPQ strategy towards secondary and tertiary students (refer to Table 1 ). Thus, after reviewing and analyzing the past studies, the researchers propose this study to identify the perception of the primary school pupils towards GRPQ strategy in reading comprehension

Table 1. Previous researches conducted across the world related to GRPQ strategy.

\begin{tabular}{|c|c|c|c|c|}
\hline Author(s) & Year & Design & $\mathbf{N}$ & Focus \\
\hline \multicolumn{5}{|l|}{ Local context } \\
\hline Tan, Tan \& Norlida & 2011 & Quasi-experimental & 68 Sixth-Form students & $\begin{array}{c}\text { The effects of Reciprocal Peer Questioning (RPQ) } \\
\text { Strategies on reading comprehension }\end{array}$ \\
\hline Shamsiah, Wong \& Chan & 2011 & Quantitative & 111 college students & $\begin{array}{c}\text { The effectiveness of Reciprocal Peer Questioning (RPQ) } \\
\text { in supporting Blended learning }\end{array}$ \\
\hline $\begin{array}{l}\text { Nurul Nadwa, Noor Dayana, } \\
\text { Noraffandy \& Meijden }\end{array}$ & 2020 & Case study & $\begin{array}{l}29 \text { undergraduate } \\
\text { students }\end{array}$ & $\begin{array}{c}\text { The patterns of critical thinking processing in online } \\
\text { Reciprocal Peer Questioning (RPQ) through Facebook } \\
\text { discussion }\end{array}$ \\
\hline \multicolumn{5}{|l|}{ International context } \\
\hline Pan & 2014 & Quasi-experimental & 78 EFL college students & $\begin{array}{c}\text { The effects of Reciprocal Peer Questioning (RPQ) to } \\
\text { enhance English reading comprehension }\end{array}$ \\
\hline Tanaka \& Sanchez & 2016 & Quantitative & 20 college students & $\begin{array}{l}\text { To investigate the perceptions of reading through peer } \\
\text { questioning in cooperative learning }\end{array}$ \\
\hline Yuniarti, Rufinus \& Wijaya & 2019 & $\begin{array}{l}\text { Pre-experimental } \\
\text { study }\end{array}$ & $\begin{array}{l}34 \text { eighth grade } \\
\text { students }\end{array}$ & $\begin{array}{l}\text { To investigate the use of Reciprocal Questioning strategy } \\
\text { in teaching reading comprehension }\end{array}$ \\
\hline DOI: $10.4236 /$ ce. 2021.1271 & & & 1651 & Creative Education \\
\hline
\end{tabular}


lessons.

This study will utilize a mixed methods research. This is appropriate as the researchers aim to investigate the perception of primary school pupils on the use of Guided Reciprocal Peer Questioning (GRPQ) strategy towards their reading comprehension skills. Questionnaire, semi-structured interview and also observation note will be used as data collection tools. All of the data collected from these methods will serve the purpose of fulfilling the research objective below:

- To investigate the perception of Year 5 pupils on the use of Guided Reciprocal Peer Questioning (GRPQ) strategy towards their reading comprehension skills.

\section{Participants and Settings}

The participants in this study will include 34 Year 5 pupils, which are selected based on the criteria of the study. For this study, participants are selected based on purposive sampling. The criteria of the participants are 11 years old and all of them must have almost the same level of reading proficiency in English. The participants must also possess basic reading skill that can allow them to read independently. These criteria will help the researchers to select the participants easier according to the specific characteristics among the population of interest (Williamson \& Johanson, 2013). As to abide the research ethics, only volunteers are considered as research participants (Merriam, 2009). Parents' consent and the participants' willingness will be the utmost important aspects to be considered for the participants' selection. This is followed by issuing letters or certificates to inform the parents on the participation of their children in this study.

\section{Conclusion}

There are many studies done by researchers across the globe and locally on the implementation of GRPQ strategy. The findings indicate positive outputs and feedback from the respondents. Most of the studies reported successful outcomes in the area of improving reading comprehension (Tan et al., 2011; Shamsiah et al., 2011; Pan, 2014; Yuniarti et al., 2019) as well as positive perception towards the use of the strategy (Tanaka \& Sanchez, 2016) and also promoting active engagement as well as higher critical thinking skill (Nurul Nadwa et al., 2020). Nevertheless, the primary school pupils seem to be excluded from all the studies and that the studies on them are still very limited, hence, providing reasons for the researchers to pursue this study.

The findings of this study will probably benefit and shed some light on the necessity of the implementation of the GRPQ strategy in reading comprehension lesson especially towards the primary school pupils. It is hoped that this study can become the stepping stone for the teachers and educators to employ Guided Reciprocal Peer Questioning (GRPQ) strategy to create meaningful and effective reading comprehension lessons that engage their pupils more and promote not only their cognitive development but also their social growth. For the most part, the teaching and learning process must be able to promote a wholesome growth 
of the learners.

To sum up everything that has been stated so far, it is hoped that this study will produce findings that can act as a catalyst towards providing the general input of the usefulness of GRPQ strategy in reading comprehension lessons of the pupils in primary school. It is also hoped that the findings can add value to the existing studies on the perception and usefulness of the strategy.

\section{Acknowledgements}

The publication of this paper is funded by the faculty of education of Universiti Kebangsaan Malaysia (UKM).

\section{Conflicts of Interest}

The authors declare no conflicts of interest regarding the publication of this paper.

\section{References}

Amalia, A. R., \& Devanti, Y. M. (2016). The Use of Questioning Strategy to Improve Students' Reading Comprehension. Journal of English Language, Literature and Teaching, 1, 81-88. https://doi.org/10.32528/ellite.v1i2.465

Amalia, K. R., \& Muhammadun, M. (2018). Using of Reciprocal Questioning to Improve Students' Reading Skill in Descriptive Text. Inspiring: English Education Journal, 1, 66-77. https://doi.org/10.35905/inspiring.v1i1.834

Amelia, R., \& Kamalasari, J. (2018). The Effect of Using KWL Plus (Know, Want, Learn, Plus Mapping and Summarizing) Strategy on Students' Reading Comprehension. Indonesian Journal of Intergrated English Language Teaching, 1, 123-132.

Bearison, D. J. (1982). New Directions in Studies of Social Interactions and Cognitive Growth. In F. C. Sarafica (Ed.), Social-Cognitive Development in Context (pp. 199-221). Guilford.

Flood, J. S., \& Peter, H. (1984). Language and the Language Arts. Prentice-Hall, Inc.

Gelmini-Hornsby, G., Ainsworth, S., \& O’Malley, C. (2011). Guided Reciprocal Questioning to Support Children's Collaborative Storytelling. Computer-Supported Collaborative Learning, 6, 577-600. https://doi.org/10.1007/s11412-011-9129-5

Hesham, S. A. (2006). Teaching Reading Comprehension to ESL/EFL Learners. Journal of Language and Learning, 1, 63-73.

King, A. (2002). Structuring Peer Interaction to Promote High-Level Cognitive Processing. Theory into Practice, 41, 34-41. https://doi.org/10.1207/s15430421tip4101 6

Matinde, E. (2019). Students' Perceptions on Reciprocal Peer Tutorial Assessment in an Undergraduate Course in Process Metallurgy. Education Science, 9, 27. https://doi.org/10.3390/educsci9010027

Merriam, S. B. (2009). Qualitative Research: A Guide to Design and Implementation. Jossey-Bass.

Natter, H. M., \& Berry, D. C. (2005). Effects of Active Information Processing on the Understanding of Risk Information. Applied Cognitive Psychology, 19, 123-135.

https://doi.org/10.1002/acp.1068

Nurul Nadwa, Z., Noor Dayana, A. H., Noraffandy, Y., \& Meijden, H. V. D. (2020). Patterns of Critical Thinking Processing in Online Reciprocal Peer Tutoring through Fa- 
cebook Discussion. IEEE Access Journal, 8, 24269-24283.

https://doi.org/10.1109/ACCESS.2020.2968960

Pan, C. Y. (2014). Effects of Reciprocal Peer-Questioning Instruction on EFL College Students' English Reading Comprehension. International Journal of English Language and Literature Studies, 3, 190-209.

Pan, C. Y., \& Wu, H. Y. (2013). The Cooperative Learning Effects on English Reading Comprehension and Learning Motivation of EFL Freshmen. Journal of English Language, Literature and Teaching, 6, 13-27. https://doi.org/10.5539/elt.v6n5p13

Shamsiah, B. M. H., Wong, L. S., \& Chan, C. T. (2011). The Effectiveness of Reciprocal Peer Tutoring in Supporting Blended Learning in Both Online and Offline Modes. INTI Journal: Special Issue on Teaching and Learning, 1, 47-57.

Tan, O. L. C., Tan, K. E., \& Ahmad, N. (2011). Effects of Reciprocal Teaching Strategies on Reading Comprehension. The Reading Matrix, 11, 140-149.

Tanaka, M., \& Sanchez, E. (2016). Students' Perceptions of Reading through Peer Questioning in Cooperative Learning. The Electronic Journal for English as a Second Language, 19, 16.

Vygotsky, L. S. (1978). Mind in Society: The Development of Higher Psychological Processes. Harvard University Press.

Williamson, K., \& Johanson G. (2013). Research Methods: Information, Systems and Contexts. Tilde University Press.

Yuniarti, Rufinus, A., \& Wijaya, B. (2019). The Use of Reciprocal Questioning (REQUEST) Strategy in Teaching Reading Comprehension. Jurnal Pendidikan dan Pembelajaran Un$\tan , 3,1-7$. 